\title{
Microplastics as a potential risk for aquatic environment organisms - a review
}

\author{
Aneta Hollerová ${ }^{1,2}$, Nikola Hodkovicová2, Jana Blahová1, Martin Faldyna², \\ Petr Maršálek ${ }^{1}, Z_{\text {deňka Svobodová }}^{1}$
}

${ }^{1}$ University of Veterinary and Pharmaceutical Sciences Brno, Faculty of Veterinary Hygiene and Ecology,

Department of Animal Protection and Welfare and Veterinary Public Health, Brno, Czech Republic

${ }^{2}$ Veterinary Research Institute, Department of Infectious Disease and Preventive Medicine, Brno, Czech Republic

Received September 30, 2020

Accepted February 24, 2021

\begin{abstract}
In the modern world, plastic has become a major commodity on global scale and is presented in all life aspects. The production of plastics is increasing dramatically throughout the world and is considered to be a serious threat for the aquatic environment. Scientists started to raise questions as to where all the disappeared plastic debris had gone, as the plastic material is a persistent synthetic polymer. The disappearance of plastic suggests that microplastics are generated by fragmentation of larger plastic debris. They also enter the aquatic environment from the cosmetics, clothing, and other industrial manufacturing. Microplastic particles spread in the aquatic, terrestrial, and atmospheric environments due to their small size and ubiquity, showing their high bioavailability. The presence of microplastics has been demonstrated in the digestive tracts of most aquatic organisms at various trophic levels. Evidence of negative effects of microplastics has been found in relation to fertility, mortality, oxidative stress, immune system or metabolic processes.
\end{abstract}

Fish, pollution, toxicity, aquatic ecosystem, bioavailabitity

In recent years, the production of plastic materials has shown a dramatic growth worldwide. Their ever-expanding use leads to their subsequent entry into the environment, where these substances pose a significant risk to living organisms. Most discussed is the effect of residues of plastic materials on aquatic organisms. Products made of plastic have a number of advantageous production properties, in particular the resistance to external influences. Low weight is also an important feature, which, however, makes them an environmental risk, as they are able to be transported through the environment over long distances. Environmental studies show that 60 to $80 \%$ of all global waste is made up of plastic. Due to their excessive use, increasing production of plastic products and their inappropriate recycling, up to $10 \%$ of plastic fragments end up in the oceans (Derraik 2002; Ivleva et al. 2017; Li et al. 2018). Most plastic materials decompose very slowly in the environment and can last there for several decades up to hundreds of years. Degradation is most often caused by sunlight, oxidation, mechanical abrasion or a combination of the above mentioned. Various factors often influence the fragmentation of plastics into smaller particles, which are generally divided according to their size into macroplastics $(>20 \mathrm{~mm})$, mesoplastics $(2-20 \mathrm{~mm})$ and microplastics $(<2 \mathrm{~mm})$ (Ryan et al. 2009; Gregory and Andrady 2011). The presence of microplastics has been demonstrated in samples of many aquatic organisms throughout the food chain of the aquatic environment (e.g. zooplankton, crustaceans and fish) (Cole et al. 2013; Kaposi et al. 2014). The presence of these contaminants has also been confirmed in fish and seafood organisms intended for human consumption. Therefore, microplastics can pose a significant health risk to humans (Rochman et al. 2015). Bioaccumulation has also been found in case of microplastics, where the increased trophic levels contain higher concentrations of microplastics than lower levels (Bouwmeester et al. 2015). Consumption of these particles can generally 
cause mechanical damage or obstruction of the digestive tract, which in turn leads to the prevention of proper absorption of nutrients. In addition, there is a possibility that smaller particles are able to penetrate through the intestinal wall and be transported to other tissues (Kaposi et al. 2014).

\section{Formation of microplastics}

Based on the way of microplastics formation, we can divide these particles into primary and secondary. Primary microplastics are produced on purpose by grinding or extrusion for subsequent use, e.g., in cosmetics and cleaning products as an abrasive. Other primary microplastics are used in industry as powdered resins or pellets and raw materials for the production of plastic products (Gregory 1996; Browne 2015). Secondary microplastics are formed spontaneously by fragmentation of larger plastic objects. This fragmentation may occur before the actual entry into the environment in the form of, e.g., synthetic fibres released mainly by washing and drying, or by environmental influences (Andrady 1998; Browne et al. 2011).

\section{Types of microplastics}

Today, we encounter several types of microplastics with different specific properties, which are also mutually combinable. The most important chemical representatives are polyethylene (PE), polypropylene (PP), polystyrene (PS), polyvinyl chloride (PVC), polyamide (PA) and polyethylene terephthalate (PET). Their behaviour in water is determined mainly by their density, which affects not only the position in the water column, but also the possible interaction with organisms (Wright et al. 2013). Higher-density plastics, such as PVC, sink to the bottom in water, whereas lower-density plastics move more easily in the water column. Polymers such as PS or PP exhibit this property (Table 1). The behaviour of microplastics in water is also affected by their biological pollution (bacterial biofilms, algae growth, etc.). Such polluted polymers have a higher weight and their sedimentation is thus further accelerated (Ye and Andrady 1991).

Table 1. The most common types of plastics and their average density (Scientific Polymer Products 2020)

\begin{tabular}{lclc}
\hline Types of plastics & $\begin{array}{r}\text { Average density } \\
\left(\mathrm{g} / \mathrm{cm}^{3}\right) \text { at } 20{ }^{\circ} \mathrm{C}\end{array}$ & Types of plastics & $\begin{array}{r}\text { Average density } \\
\left(\mathrm{g} / \mathrm{cm}^{3}\right) \mathrm{at} 20^{\circ} \mathrm{C}\end{array}$ \\
\hline Polyolefins & & Acrylates & 1.20 \\
HDPE (High density polyethylene) & 0.95 & PMMA (Polymethyl methacrylate) & Polyamides \\
LDPE (Low density polyethylene) & 0.92 & PA (Polyamide) & 1.30 \\
PP (Polypropylene) & 0.90 & Polyesters & 1.40 \\
Chlorinated plastics & & PET (Polyethylene terephthalate) & 1.20 \\
PVC (Polyvinyl chloride) & 1.40 & PC (Polycarbonate) & \\
Styrene plastics & & & \\
PS (Polystyrene) & 1.50 & & \\
\hline
\end{tabular}

The different properties of individual types of plastics are mainly caused by the shape of their macromolecules. We distinguish between linear, branched, and crosslinked macromolecules. Linear macromolecules, such as high-density PE (HDPE), have a higher density, strength and flexibility. On the contrary, molecules with a branched structure have a lower density, strength and flexibility, e.g. low-density PE (LDPE). The properties of crosslinked polymers depend on the density of the network, which means that the strength, flexibility and durability increase with the higher density (Sharma et al. 2004; Setälä et al. 2014). 
Components of plastic materials, such as their monomers and various additives used to modify their properties, can be released into the environment during use and disposal, posing a potential hazard. For example, mutagenic and carcinogenic effects are attributed to the styrene monomer (Lithner et al. 2011). Several additives used in the production of plastics have been identified as dangerous in the past (e.g. due to their carcinogenicity, nephrotoxicity, hepatotoxicity) and their use has been significantly limited. These are in particular polybrominated flame retardants, lead heat stabilizers or phthalate plasticizers. These dangerous substances can enter organisms through microplastics and adversely affect animal and human health (Halden 2010; Lithner et al. 2011).

\section{The occurrence of microplastics in the aquatic environment}

\section{Microplastic occurrence in freshwater sources}

Nowadays, microplastics are detected in freshwater sources and sediments around the world. Factors influencing their distribution and occurrence in freshwater are both environmental (e.g. floods, storms) and anthropogenic (e.g. wastewater contamination, road outfall) (Eriksen et al. 2013; Eerkes-Medrano et al. 2015). The most important factor is the population density and urbanization of the area. Higher concentrations of microplastics are detected in wastewater in densely populated urban areas (Paul-Pont et al. 2016). The soil can only partially retain these particles, and the microplastics can thus be transported to groundwater (Wong et al. 2020). Analyses of drinking water in Germany showed the presence of microplastics in $62 \%$ of samples from 5 different territorial regions (Mintenig et al. 2019). In the state of Illinois in the USA, up to $94 \%$ of the tested samples showed a positive result for the presence of these contaminants (Kelly et al. 2019).

Most microplastics enter freshwater from secondary sources, mainly through the fragmentation of larger plastic objects (e.g. packaging materials, tires, synthetic fibres) through surface and agricultural runoff or poor waste management. Another no less important source of contamination is the discharge of insufficiently treated water from treatment plants, where often highly contaminated wastewater from households enters (Free et al. 2014). The results of scientific studies in this area may differ due to different methods of sampling and detection, and may be affected by spatial, temporal, and seasonal variability (Dris et al. 2015; Leslie et al. 2017). Most microplastics, up to $95 \%$, can be captured in the first stages of purification. However, taking into account the significant volume of water produced by wastewater treatment plants, we must include this water among the main sources contaminating the freshwater environment with microplastics (Li et al. 2018).

River systems can exhibitvery different patterns of particle properties(size, shape, composition) based on the sources of waste located in their vicinity and on the distance downstream. The particle transport in freshwater systems is affected by physical properties such as the flow rate and depth, bottom topography or seasonal level fluctuations. Adverse flow conditions or flow level fluctuations can lead to increased particle deposition. Stronger hydrodynamic conditions, on the other hand, can lead to the mobilization of sedimented particles and their subsequent release into the environment (Wang et al. 2017; Kataoka et al. 2019).

\section{Microplastic occurrence in the seas and oceans}

Microplastics enter the seas and oceans through plastic waste via two main inputs, directly by discharging the waste from ocean ships or land-based sources such as polluted rivers, sewers, wind or polluted shores (Table 2). Near the coast, the concentration of total waste is higher than on the high seas, but the share of plastics in seawater waste increases with the distance from land. This fact is due to the lower density of most plastics, which makes 
these materials easier to transport compared to glass or metals. These plastic fragments are often carried across the oceans, contaminating even the most remote corners of the world (Coe et al. 1997; Barnes 2002). In addition, such waste can accumulate in the oceans and form so-called plastic islands (Pichel et al. 2007).

Table 2. Occurrence of microplastics in the oceans (Kutralam-Muniasamy et al. 2020).

\begin{tabular}{|c|c|c|c|c|c|c|c|}
\hline Location & Matrix & $\begin{array}{c}\text { Positive } \\
\text { samples (\%) }\end{array}$ & $\begin{array}{c}\text { Used } \\
\text { filters }(\mu \mathrm{m})\end{array}$ & $\begin{array}{c}\text { Particle } \\
\text { size }(\mu \mathrm{m})\end{array}$ & $\begin{array}{l}\text { Particle } \\
\text { shape }\end{array}$ & $\begin{array}{c}\text { Particle } \\
\text { colour }\end{array}$ & $\begin{array}{c}\text { Particle } \\
\text { type }\end{array}$ \\
\hline Tyrrhenian Sea & Sediment & 100 & 1000 & $\leq 5000$ & Threads & $\begin{array}{l}\text { Blue, red, } \\
\text { purple, } \\
\text { translucent }\end{array}$ & $\begin{array}{l}\text { Nylon, } \\
\text { polyurethane, } \\
\text { PE, PET }\end{array}$ \\
\hline Shanghai, China & $\begin{array}{l}\text { Water, } \\
\text { Sediment }\end{array}$ & 100 & 8 & $\begin{array}{l}1000- \\
5000\end{array}$ & Threads & $\begin{array}{l}\text { Blue, } \\
\text { translucent }\end{array}$ & $\begin{array}{l}\text { PE, PP, } \\
\text { cellophane }\end{array}$ \\
\hline $\begin{array}{l}\text { San Francisco } \\
\text { Bay }\end{array}$ & $\begin{array}{l}\text { Water } \\
\text { surface }\end{array}$ & 100 & 333 & $\begin{array}{l}355- \\
4700\end{array}$ & Threads & $\mathrm{x}$ & $\mathrm{x}$ \\
\hline Japan & $\begin{array}{l}\text { Water } \\
\text { surface }\end{array}$ & 35 & 333 & $\mathrm{x}$ & Marbles & $\mathrm{x}$ & PE \\
\hline $\begin{array}{l}\text { Punta del Este, } \\
\text { Uruguay }\end{array}$ & $\begin{array}{l}\text { Water } \\
\text { surface }\end{array}$ & 100 & 300 & $\mathrm{x}$ & $\mathrm{x}$ & $\begin{array}{l}\text { Yellow, } \\
\text { translucent, }\end{array}$ & $\begin{array}{l}\text { PE, PP } \\
\text { Polyester, } \\
\text { PE }\end{array}$ \\
\hline North Sea & $\begin{array}{l}\text { Water } \\
\text { surface }\end{array}$ & 100 & 0.45 & $\begin{array}{l}1000- \\
5000\end{array}$ & Threads & $\begin{array}{l}\text { black } \\
\text { Blue, red, } \\
\text { white, } \\
\text { yellow, black }\end{array}$ & \\
\hline
\end{tabular}

$\mathrm{PE}$ - polyethylene, $\mathrm{PET}$ - polyethylene terephthalate, $\mathrm{PP}$ - polypropylene, $\mathrm{x}$ - data not available

\section{Toxicity of microplastics to aquatic organisms}

The toxicity of microplastics for aquatic organisms is affected by a number of factors, such as their type, size, or concentration. The most useful studies are those that deal with only one variable, where only one property of the polymer is changed and at the same time all exposure conditions are constant.

The impact of the microplastic type

Most evidence for the uptake of microplastics by fish organisms comes from studies of the contents of their digestive tract, where various colours, shapes, and types of these particles are found. The most frequently detected shapes include fibres and fragments, which directly correlates with the occurrence of these shapes in the world waters (Lusher et al. 2013; Alomar and Deudero 2017). Polyethylene, PP and polyesters are the most commonly found types of polymers in the digestive tract of fish. The oral intake of particles can occur directly as a result of confusion with prey or indirectly through consumption of contaminated organisms. In addition to the presence of microplastics in the stomach and intestines, they may also adhere to the scales or translocate through cells to the circulatory or lymphatic system and be transported to other tissues such as the gills, liver, and muscles (Abdel-Khalek et al. 2016; Su et al. 2018).

A number of studies have shown significant effects on the antioxidant and detoxification system of aquatic organisms. There are two chemical properties of microplastics that underlie the different reactions of redox biomarkers of the antioxidant system associated with polymer types. The first aspect is the polymers themselves differing in the main 
chemical chain, the types and numbers of side chains deviating from the main chain. The second chemical aspect that could contribute to the specific responses of the organism is the residual monomers and additives (Andrady and Neal 2009). These mobile substances can further interact with the antioxidant system and contribute to the reactions of redox biomarkers such as catalase (CAT), glutathione peroxidase (GPx) and glutathione S-transferase (GST) (Jemec et al. 2012; Lambert et al. 2017).

Some types of microplastics of the same size (PE, PP, PVC) significantly increase the gene expression of the enzyme GST, while the PA did not cause any transcriptional change, as demonstrated by study on zebrafish and nematodes (Lei et al. 2018a). The GST enzyme is responsible for detoxification from foreign substances and oxidized lipids disrupting redox homeostasis (Halliwell and Gutteridge 2015). An increased sensitivity in Eisenia invertebrates was demonstrated in the study of antioxidant enzyme changes, when, after the exposure to various concentrations of PS and low-density PE, there was a significant increase in the peroxidase and catalase activity, which are involved in the removal of peroxide produced by aerobically breathing cells (Wang et al. 2019).

The surface of microplastics can also have different effects on the organism. An irregular surface of the particles burdens more the antioxidant system. This also affected another key factor in determining the condition of fish, namely their behaviour, when there was a significant reduction in their physical activity. Sharper particles can then cause more severe tissue damage. This fact suggests that more frequently occurring irregularly shaped particles may be more dangerous than particles of a regular shape (Choi et al. 2018).

\section{The impact of the microplastic particle size}

Another important factor influencing the toxicity of microplastics is their size, as it is closely related to the amount of particles and the residence time in the digestive tract. Gray and Weinstein (2017), for example, studied this issue when evaluating the effects of PS on the shrimp species Palaemonetes paludosus. They found that the exposure to $75 \mu \mathrm{m}$ particles resulted in a longer retention in the gut than the exposure to $30 \mu \mathrm{m}$ particles with subsequent higher mortality (up to $55 \%$ compared to the control sample). This result was attributed to the gastrointestinal obstruction, as clusters of microparticles were found in the gastrointestinal tract of all dead individuals. Sufficiently small particles can penetrate the intestinal wall into the haemolymph and thus be transported to other tissues. This fact was observed in an experiment on edible mussels (Mytillus edulis). After the exposure of PS to $3 \mu \mathrm{m}$ particles, up to $60 \%$ more microparticles were detected in their haemolymph than after the exposure to $9.6 \mu \mathrm{m}$ large particles. The explanation for this is that smaller particles are more easily phagocytosed, probably due to the fact that phagosomes located in cells receive higher amounts of smaller particles. The accumulation of smaller microplastics is thus a frequent part of the metabolism of microplastic degradation (Browne et al. 2008).

The size of microplastic particles also significantly affects the gene expression. Most studies report that significant differences in the GST gene expression are mainly due to smaller microplastic particle sizes. For instance, Lei et al. (2018b) found in their study on Caenorhabditis nematodes that the expression of this gene was significantly increased when exposed to the PS particles with a size of $1 \mu \mathrm{m}$ compared to the group exposed to $5 \mu \mathrm{m}$ particles.

\section{The impact of microplastic concentration}

Another studied factor that significantly affects the toxicity of microplastics is the effect of the concentration of the particles. The results of studies in this area are very incomplete, especially in terms of reported units (e.g. $\mathrm{mg} / \mathrm{l}$, number of particles $/ \mathrm{ml}$ ) (Hamed et al. 2019). This topic is most frequently covered by studies aimed at influencing biochemical and haematological indices. 
Out of the biochemical indices, significant changes in the concentration of creatinine, uric acid, glucose, total protein, albumin, globulin and also the activities of the enzymes aspartate transaminase (AST), alanine aminotransferase (ALT) and alkaline phosphatase (ALP) were demonstrated. During the experiment on the Nile tilapia (Oreochromis niloticus) there was an increase in the above indicators after the exposure to microplastics at concentrations of 1,10 and $100 \mathrm{mg} / 1$ in a 15-day test compared to the control group. Unfortunately, the type of microplastic was not specified in the study (Hamed et al. 2019). Creatinine and uric acid can be considered as biomarkers of proper kidney function. The effect of microplastics is to decrease glomerular filtration, reduce creatinine excretion and increase its serum concentration. The increased concentration of uric acid is associated with cell breakdown, specifically the degradation of purine bases released from nucleic acids (Abdel-Khalek et al. 2016). An increase in the concentration of glucose in the blood indicates the body's response to a stressful situation (Banaee et al. 2016). Proteins play a vital role in maintaining proper body homeostasis. An increase in albumin levels is an indicator of a poor liver and kidney function, and the increase in globulins is an indicator of the immune system's defence response (Espinos a et al. 2019). The enzymes AST, ALT, ALP and lactate dehydrogenase (LDH) are present in various organs and their increased activities are considered to be the indicators of cell membrane damage. An increase in serum ALT signals liver damage. The LDH occurs in the cytoplasm of all cells and its concentration in tissues is about $500 \times$ higher than in serum, so even with minimal damage to cell membranes, the LDH is elevated in serum. It is a non-specific but very accurate biomarker of hepatocyte, erythrocyte or leukocyte damage. Alkaline phosphatase is an enzyme that catalyses the degradation of phosphoric acid esters involved in the process of osteogenesis (Kiba 2005). In addition to biochemical changes, numerous changes in haematological indices have been recorded that significantly reflect the health condition of fish. There was a significant reduction in erythrocytes, leukocytes and platelets after the exposure. Furthermore, a significant reduction in blood haemoglobin, haematocrit and mean corpuscular haemoglobin concentration was confirmed (Hamed et al. 2019). Decreases in the erythrocyte count, haemoglobin concentration and haematocrit may also be caused by haemolysis due to the toxic effects of microplastics. The decrease in the total number of white blood cells may be caused by the negative effect of microplastics on the lymphoid tissues of exposed fish (Espinosa et al. 2019).

There are several reasons why antioxidant biomarkers do not respond to microplastics concentration in the same way. The first reason is that the threshold value for the concentration of oxidative stress particles for organisms varies significantly between individuals of the same species. This increased variability of the measured biomarkers may indicate an individual's ability to adapt to an environment polluted by microplastics (Devin et al. 2014).

\section{Bioavailability of microplastics for fish organisms}

Microplastics are present in almost all types of aquatic habitats and in similar proportions as most sediment and planktonic organisms, making these particles highly bioavailable to a wide variety of aquatic organisms, including fish. This availability can be affected by many factors. Plankton and benthos-feeding fish are generally considered to be more susceptible than predatory fish (Kumar et al. 2018). The vast majority of fish are visual predators, and the likelihood of consuming particles that are similar in appearance to their prey is very high. This fact was addressed in a study on juvenile individuals of the common goby (Pomatoschistus microps). It reports that in comparison with black and red microplastics, white microplastics were preferentially consumed, being easily mistaken for white shrimp (Artemia nauplii) which are strategic prey for the goby (Auta et al. 2017). 


\section{Conclusion}

Microplastics are a major problem for aquatic ecosystems due to their countless potential risks and bioavailability. In addition, these contaminants may increase the potential for various chemicals to enter the aquatic environment, which can lead to additional environmental risks. Their ability to accumulate in the digestive tract of aquatic organisms can subsequently cause its structural and functional damage with a gradual reduction in food intake and growth retardation. Microplastics can further stimulate inflammatory reactions, adversely affect metabolism or disrupt the immune system. Another problem is their permeability through the intestinal wall to other organs and tissues, such as fish muscle, and thus affect human health ( $\mathrm{Lu}$ et al. 2016; Jabeen et al. 2018). The variability of microplastics in the freshwater and terrestrial environments is of major concern. Microplastics are known to have entered the food chain. A risk assessment of their toxicity needs to be carried out, and the best management practices for microplastics need to be developed and adapted. Their formation, fragmentation, and degradation mechanisms are especially important for fundamental scientific understanding. There are many processes (physicochemical, biological pathways) that need to be understood more deeply. Plastic litter in freshwater and marine sources is expected to increase over the next decades, so this problem will be the subject of a number of scientific studies.

\section{Acknowledgements}

This article was financially supported by the project IGA VFU 212/2019/FVHE and ERDF/ESF "PROFISH" no. CZ.02.1.01/0.0/0.0./16_019/0000869.

\section{References}

Abdel-Khalek AA, Badran SR, Marie MA 2016: Toxicity evaluation of copper oxide bulk and nanoparticles in Nile tilapia, Oreochromis niloticus, using hematological, bioaccumulation and histological biomarkers. Fish Physiol Biochem 42: 1225-1236

Alomar C, Deudero S 2017: Evidence of microplastic ingestion in the shark Galeus melastomus Rafinesque, 1810 in the continental shelf off the western Mediterranean Sea. Environ Pollut 223: 223-229

Andrady AL 1998: The plastic in microplastics: A review. Mar Pollut Bull 119: 12-22

Andrady AL, Neal MA 2009: Applications and societal benefits of plastics. Philos Trans R Soc B-Biol Sci 364: 2153-2166

Auta HS, Emenike C, Fauziah S 2017: Distribution and importance of microplastics in the marine environment: A review of the sources, fate, effects, and potential solutions. Environ Int 102: 165-176

Banaee M, Nemadoost Haghi B, Tahery S, Shahafve S, Vaziriyan M 2016: Iran J Toxicol 10: 1-5

Barnes DKA 2002: Invasions by marine life on plastic debris. Nature 416: 808-809

Bouwmeester H, Hollman PC, Peters RJ 2015: Potential health impact of environmentally released micro- and nanoplastics in the human food production chain: experiences from nanotoxicology. Environ Sci Technol 49: 8932-8947

Browne MA, Dissanayake A, Galloway TS, Lowe DM, Thompson RC 2008: Ingested microscopic plastic translocates to the circulatory system of mussel, Mytilus edulis (L). Environ Sci Technol 42: 5026-5031

Browne MA, Crump P, Niven SJ, Teuten E, Tonkin A, Galloway T, Thompson RC 2011: Accumulation of microplastic on shorelines worldwide: sources and sinks. Environ Sci Technol 45: 9175-9179

Browne MA 2015: Sources and pathways of microplastics to habitats. Springer, Cham, 229 p.

Choi JS, Jung YJ, Hong NH, Hong SH, Park JW 2018: Toxicological effects of irregularly shaped and spherical microplastics in a marine teleost, the sheepshead minnow (Cyprinodon variegatus). Mar Pollut Bull 129: 231-240

Coe JM, James M, Rogers DB 1997: Marine debris: sources, impacts, and solutions. Springer-Verlag, New York, 432 p.

Cole M, Lindeque P, Fileman E, Halsband C, Goodhead R, Moger J, Galloway TS 2013: Ingestion of microplastics by zooplankton in the northeast Pacific Ocean. Environ Sci Technol 69: 320-330

Derraik JG 2002: The pollution of the marine environment by plastic debris: a review. Mar Pollut Bull 44: 842-852

Devin S, Giamberini L, Pain-Devin S 2014: Variation in variance means more than mean variations: what does variability tell us about population health status. Environ Int 73: 282-287

Dris R, Gasperi J, Saad M, Renault N, Tassin B, Rocher V 2015: Sources and fate of microplastics in urban areas: A focus on Paris megacity. Freshwater microplastics. The Handbook of the environmental chemistry. Springer, Cham, $69 \mathrm{p}$

Eerkes-Medrano D, Thompson RC, Aldridge DC 2015: Microplastics in freshwater systems: A review of emerging threats, identification of knowledge gaps and prioritisation of research needs. Water Res 75: 63-82 
Eriksen M, Mason S, Wilson S, Box C, Zellers A, Edwards W, Farley H, Amato S 2013: Microplastic pollution in the surface waters of Laurentian Great Lakes. Mar Pollut Bull 77: 177-182

Espinosa C, Cuesta A, Esteban MA 2019: Dietary administration of PVC and PE microplastics produces histological damage, oxidative stress and immunoregulation in European sea bass (Dicentrarchus labrax L.). Fish Shellfish Imunnol 95:574-583

Free CM, Jensen OP, Mason SA, Eriksen M, Williamson NJ, Boldgiv D 2014: High-levels of microplastic pollution in large, remote, mountain lake. Mar Pollut Bull 85: 156-163

Gray AD, Weinstein JE 2017: Size- and shape-dependent effects of microplastic particles on adult daggerblade grass shrimp (Palaemonetes pugio). Environ Toxicol Chem 36: 3074-3080

Gregory MR 1996: Plastic 'scrubbers' in hand cleansers: a further (and minor) source for marine Pollution identified. Mar Pollut Bull 32: 867-871

Gregory MR, Andrady AL 2011: Microplastics in the marine environment. Mar Pollut Bull 62: 1596-1605

Hamed M, Soliman HAM, Osman AGM, Sayed AE-DH 2019: Assessment the effect of exposure to microplastics in Nile Tilapia (Oreochromis niloticus) early juvenile: I. blood biomarkers. Chemosphere 228: 345-350

Halden RU 2010: Plastics and health risks. Annu Rev Publ Health 31: 179-194

Halliwell B, Gutteridge JMC 2015: Free radicals in biology and medicine. Acta Crys 73: 384-385

Ivleva NP, Wiesheu AC, Niessener R 2017: Microplastics in aquatic ecosystems. Angew Chem Int Ed 56: 1720-1739

Jabeen K, Li B, Chen Q, Su L, Wu C, Hollert H, Shi H 2018: Effects of virgin microplastics on goldfish (Carassius auratus). Chemosphere 213: 323-332

Jemec A, Tišler T, Erjavec B, Pintar A 2012: Antioxidant responses and whole-organism changes on Daphnia magna acutely and chronically exposed to endocrine disruptor bisphenol A. Ecotoxicol Environ Saf 86: 213-218

Kaposi KL, Mos B, Kelaher BP, Dworjanyn SA 2014: Ingestion of microplastic has limited impact on a Marine Larva 43: 1638-1645

Kataoka T, Nihei Y, Kudou K, Hinata H 2019: Assessment of the sources and inflow processes of microplastics in the river environments of Japan. Environ Pollut 244: 958-965

Kelly WR, Scott J, Zheng W, Holm N, McNeish RE, Hoellein TJ, Baranski EL, Panno SV 2019: Microplastic contamination in Karst groundwater systems. Ground Water 57: 189-196

Kiba N 2005: Enzymes in physiological samples. In: Encyclopedia of analytical science. $2^{\text {nd }}$ edn (Ed.): Elsevier, Amsterdam, $536 \mathrm{p}$.

Kumar VE, Ravikumar G, Jeyasanta KI 2018: Occurrence of microplastics in fishes from two landing sites in Tuticorin, South east coast of India. Mar Pollut Bull 135: 889-894

Kutralam-Muniasamy G, Pérez-Guevara F, Elizalde-Martínez I, Shruti VC 2020: An overview of recent advances in micro/nano beads and microfibers research: Critical assessment and promoting the less known. Sci Total Environ 740: 139991

Lambert S, Scherer Ch, Wagner M 2017: Ecotoxicity testing of microplastics: Considering the heterogeneity of physicochemical properties. Integr Environ Assess Manag 13: 470-475

Lei L, Liu M, Song Y, Lu S, Hu J, Cao C, Xie B, Shi H, He D 2018b: Polystyrene (nano)microplastics cause size-dependent neurotoxicity, oxidative damage and other adverse effects in Caenorhabditis elegans. Environ Sci Nano 5: 2009-2020

Lei L, Wu S, Lu S, Liu M, Song Y, Fu Z, Shi H, Raley-Susman KM, He D 2018a: Microplastic particles cause intestinal damage and other adverse effect in zebrafish Danio rerio and Caenorhabditis elegans. Sci Total Environ 619-620: $1-8$

Leslie HA, Brandsma SH, van Velzen MJM, Vethaak AD 2017: Microplastics en route: Field measurements in the Dutch river delta and Amsterdam canals, wastewater treatment plants, North Sea sediments and biota. Environ Int 101: 133-142

Li J, Liu H, Paul Chen J 2018: Microplastics in freshwater systems: A review on occurrence, environmental effects, and methods for microplastics detection. Water Research 137: 362-374

Lithner D, Larsson A, Dave G 2011: Environmental and health hazard ranking and assessment of plastic polymers based on chemical composition. Sci Total Environ 409: 3309-3324

Lu Y, Zhang Y, Deng Y, Jiang W, Zhao Y, Geng J, Ding L, Re, H 2016: Uptake and accumulation of polystyrene microplastics in zebrafish (Danio rerio) and toxic effects in liver. Environ Sci Technol 50: 4054-4060

Lusher AL, McHugh M, Thompson RC 2013: Occurrence of microplastics in the gastrointestinal tract of pelagic and demersal fish from the English Channel. Mar Pollut Bull 67: 94-99

Mintenig SM, Löder MGJ, Primpke S, Gerdts G 2019: Low numbers of microplastics detected in drinking water from ground water sources. Sci Total Environ 648: 631-635

Paul-Pont I, Lacroix C, González Fernández C, Hégaret H, Lambert Ch, Le Goic N, Frere L, Cassone A-L, Sussarellu R, Fabioux C, Guyomarch J, Albentosa M, Huvet A, Soudant P 2016: Exporuse of marine mussels Mytilus spp. to polystyrene microplastics: Toxicity and influence on fluoranthene bioaccumulation. Environ Pollut 216: 724-737

Pichel W, Churnside JH, Veenstra TS, Foley DG, Friedman KS, Brainard RE, Nicoll JB, Zheng Q, ClementeColon P 2007: Marine debris collects within the North Pacific Subtropical Convergence Zone. Mar Pollut Bull 54: 1207-1211 
Rochman ChM, Tahir A, Williams SL, Baxa DV, Lam R, Miller JT, Teh F-Ch, Werorilangi S, The SJ 2015: Anthropogenic debris in seafood: Plastic debris and fibers from textiles in fish and bivales sold for human consumption. Sci Rep 5: 14340

Ryan PG, Moore ChJ, van Franeker JA, Moloney CL 2009: Monitoring the abundance plastic in the marine environment. Philos Trans R Soc Lond B Biol Sci 364: 1999-2012

Scientific Polymer Products 2020: Density of Polymers (by density). Sci Polymer Products. Avaible at: www.scientificpolymer.com/density-of-polymers-by-density. Accessed April 19, 2020.

Setälä O, Fleming-Lehtinen V, Lehtiniemi M 2014: Ingestion and transfer of microplastics in the planktonic food web. Environ Pollut 185: 77-83

Sharma R, Yang Y, Sharma A, Awasthi S, Awasthi YC 2004: Antioxidant role of glutathione S-transferases: protection against oxidant toxicity and regulation of stress-mediated apoptosis. Antioxid Redox Signal 6: 289-300

Su L, Cai H, Kolandhasamy P, Wu Ch, Rochman ChM, Shi H 2018: Using the Asian clam as an indicator of microplastic pollution in freshwater ecosystem. Environ Pollut 234: 374-355

Wang J, Coffin S, Sun Ch, Schlenk D, Gan J 2019: Negligible effects of microplastics on animal fitness and HOC bioaccumulation in earthworm Eisenia fetida in soil. Environ Pollut 249: 776-784

Wang W, Ndungu AW, Li Z, Wang J 2017: Microplastics pollution in inland freshwaters of China: A case study in urban surface waters of Wuhan, China. Sci Total Environ 575: 1369-1374

Wong JKH, Lee KK, Tang KHD, Yap P-S 2020: Microplastics in the freshwater and terrestrial environments: Prevalence, fates, impacts and sustainable solutions. Sci Total Environ 719: 137512

Wright SL, Rowe D, Thompson RC, Galloway TS 2013: Microplastic ingestion decreases energy reserves in marine worms. Curr Biol 23: 1031-1033

Ye S, Andrady L 1991: Fouling of floating plastic debris under Biscayne Bay exposure conditions. Mar Pollut Bull 22: 608-613 